\title{
Effect of deposition parameters on kinematics growth and optical properties of PbS nano films deposited by chemical bath deposition
}

\author{
Ali M. Mousa*, SIma M. Hassen, S. Mohmoed \\ Department of Applied Sciences, University of Technology, Baghdad, Iraq \\ *E-mail address: alzuhery51@yahoo.com
}

\begin{abstract}
The paper presents a study regarding the kinetic of chemical bath deposition (CBD) PbS nano films. Nano films were deposited from chemical bath containing thiourea, lead nitrite, and ammonia. The deposition kinematics and optical investigations have been performed to compare the properties of the films grown with different precursor solutions. We are able to determine the growth rate as a function of the synthesis conditions and it was found that the growth rate of deposited nano layer affected significantly by synthesis conditions. The main characteristic of nano films is the band gap. This parameter determined from spectroscopy Measurements of transmission, in the energy range of $240-840 \mathrm{~nm}$ is influenced by many factors such as deposition time, bath temperature, $\mathrm{pH}$ value of the path and molar concentration of the reactants.
\end{abstract}

Keywords: nano film; chemical bath deposition; PbS films

\section{INTRODUCTION}

Tailoring material properties using nanostructures in photovoltaic offers the potential for high efficiency closer to their theoretical maximum (1). Nanometers exhibit dramatic size dependence of optical properties due to the quantum confinement effect $[2,3]$. Shape and interaction between particles can also play an important role [4-6]. The surface-to-volume ratio ( $1 / \mathrm{R}$ scaling for spherical nanoparticles with radius $\mathrm{R})$ is exceedingly large for nanomaterials, typically a million-fold increase compared to bulk. Many of their properties, including optical, are extremely sensitive to surface characteristics [7]. Lead sulfide $(\mathrm{PbS})$ has a relatively small band gap $(0.41 \mathrm{eV}$ at $300 \mathrm{~K})$. The band gap of $\mathrm{PbS}$ can be easily adjusted up to a few electron volts when in the form of nanometer sized dots. Such a significant widening of the band gap is associated with small effective masses of electrons and holes $\left(\mathrm{m}_{\mathrm{e}}=\mathrm{m}_{\mathrm{h}}=\right.$ $\left.0.09 \mathrm{~m}_{0}\right)$ as well as with a relatively large exciton Bohr radius $(20 \mathrm{~nm})$ of $\mathrm{PbS}[8,9] . \mathrm{PbS}$ film is commonly deposited using Chemical bath deposition (10,11-15), since it is a very comfortable method for deposition of polycrystalline films, at low cost meets the criteria of cheap reproducible and relatively simple process. They even offer an opportunity for a 'do-it yourself' approach to the production of device and coating [16]. Nanocrystalline PbS layers have been deposited chemically on different substrates $(17,18)$. We have investigated here the role of deposition parameters in the most common method of synthesis $\mathrm{PbS}$ nanocrystals deposited on glass substrate 


\section{EXPERIMENTAL DETAILS}

Thin films of Lead Sulfide $(\mathrm{PbS})$ are prepared by Chemical Bath Deposition Technique using aqueous. Solution of analytical grade with purity over $99.9 \%$ of $\mathrm{Pb}\left(\mathrm{NO}_{3}\right)$ (Lead nitrate) a $\mathrm{Pb}$ ion source and Thiourea a $\mathrm{S}$ - ion source in an alkaline solution of $\mathrm{NaOH}$. Commercial glass slides used as substrates were cleaned in acetone and methanol ultrasonically then left for $24 \mathrm{~h}$ in chromic acid and finally washed with doubly distilled water ultrasonically before use. The Substrates was mounted on a glass holder and were immersed vertically in the solution. A hot plate with a magnetic stirrer was used to heat and stir the bath solution.

After the deposition, the PbS films were washed with distilled water ultrasonically to remove the loosely adhered $\mathrm{PbS}$ particles on the film and finally dried in air. In total, 31 samples with different deposition conditions were examined. All the involved films have a thickness of (90-160 nm).

The Structural and Optical properties of these films are investigated. The crystallinity of the thin films was characterized by means of X-ray diffraction and they all turned out to be polycrystalline. The chemical bath deposition method is based on a chemical reaction between dissolved constituents in aqueous solutions, reaction mechanism for deposition of $\mathrm{PbS}$ in alkaline solution usually involve the formation of elemental sulfur, which is supposed to react with $\mathrm{Pb}^{2+}$ to form $\mathrm{PbS}$ [19-21].

$$
\mathrm{Pb}\left(\mathrm{CH}_{3} \mathrm{COO}\right)_{2} \rightarrow \mathrm{Pb}^{2+}+2 \mathrm{CHCOO}^{-}
$$

In alkaline medium, dissociation of $\left(\mathrm{NH}_{2}\right)_{2} \mathrm{CS}$ takes place,

$$
\begin{aligned}
& \mathrm{S} \\
& \mathrm{II} \\
& \mathrm{NH}_{2}-\mathrm{C}-\mathrm{NH}_{2}+\mathrm{OH}^{-} \rightarrow \mathrm{CH}_{2} \mathrm{~N}_{2}+\mathrm{H}_{2} \mathrm{O}+\mathrm{SH}^{-} \\
& \mathrm{SH}^{-}+\mathrm{OH}^{-} \rightarrow \mathrm{S}^{2-}+\mathrm{H}_{2} \mathrm{O} \\
& \mathrm{Pb}^{2+}+\mathrm{S}^{2-} \rightarrow \mathrm{PbS} \downarrow
\end{aligned}
$$

The Structural and Optical properties of these films are investigated. The crystallinity of the thin films was characterized by means of X-ray diffraction and they all turned out to be polycrystalline.

\section{RESULTS AND DISCUSSION}

\section{1. Growth kinetic}

A detailed study of the growth kinetics carried out at constant path volume and different deposition conditions (deposition time, different $\mathrm{PH}$ values, different path temperatures and different concentration of constituent elements) are depicted in Fig. (1 a-e). Keeping the bath temperatures at $30^{\circ} \mathrm{C}$, and $\mathrm{pH}=11.6$, Fig. (1a) indicate that the deposition times control the deposition rat. However, the deposition rate for shorter time ( $\leq 75 \mathrm{~min})$ is obviously greater than that with longer time. A steady increase in film thickness during the first 75 min the curve inclines upward slightly. 
Beyond $75 \mathrm{~min}$, the growth rate gradually slows down and then presents saturation growth after $90 \mathrm{~min}$. which are typical of CBD processes. This probably is due to a depletion of reagents in the deposition mixture. The high deposition rate and since the graph dose not extrapolated to $(0,0)$ no initial nucleation period needed and the flux deposition mechanism dominated by ion-ion mechanism. Deposited films using lead acetate (at the same PH) (18), shows much lower deposition rate comparing to the lead nitrite. Nucleation stage in the present work (of film deposited on glass substrate) is greater than those obtained with $\mathrm{Si}$ substrate using lead nitrite (17), this could be attributed to the high concentration of the reactive centers in the glass substrate since the CBD process can be controlled by the number active sites in the substrate surface [22].

The influence of the bath temperatures ranging from 5 to $70^{\circ} \mathrm{C}$ upon $\mathrm{PbS}$ film thickness has been investigated at constant lead nitrate and thiourea concentration. The dependence of $\mathrm{PbS}$ film thickness on bath temperatures is illustrated in Fig. (1b).

The film thickness increases linearly with path temperature up to $70{ }^{\circ} \mathrm{C}$ (thickness around $170 \mathrm{~nm}$ which represent a critical value) beyond which thickness start to decrease, since heating of the solution helps the decomposition of thiourea and also provides kinetic energy to the ions, resulting in increased number of collisions and hence combination to form $\mathrm{PbS}$.

No saturation behavior in the film thickness, this probably because of the non-reduction in the ionic product of $\mathrm{PbS}$ in the solution to values about the solubility product

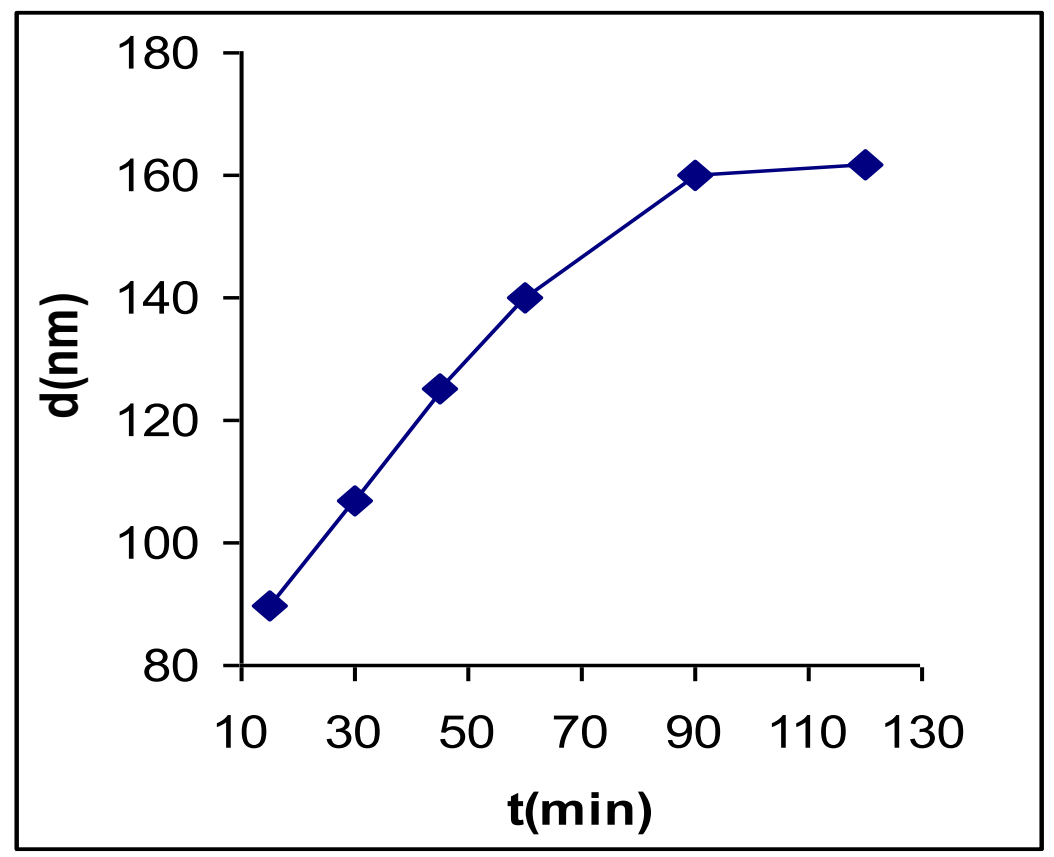

(a) 


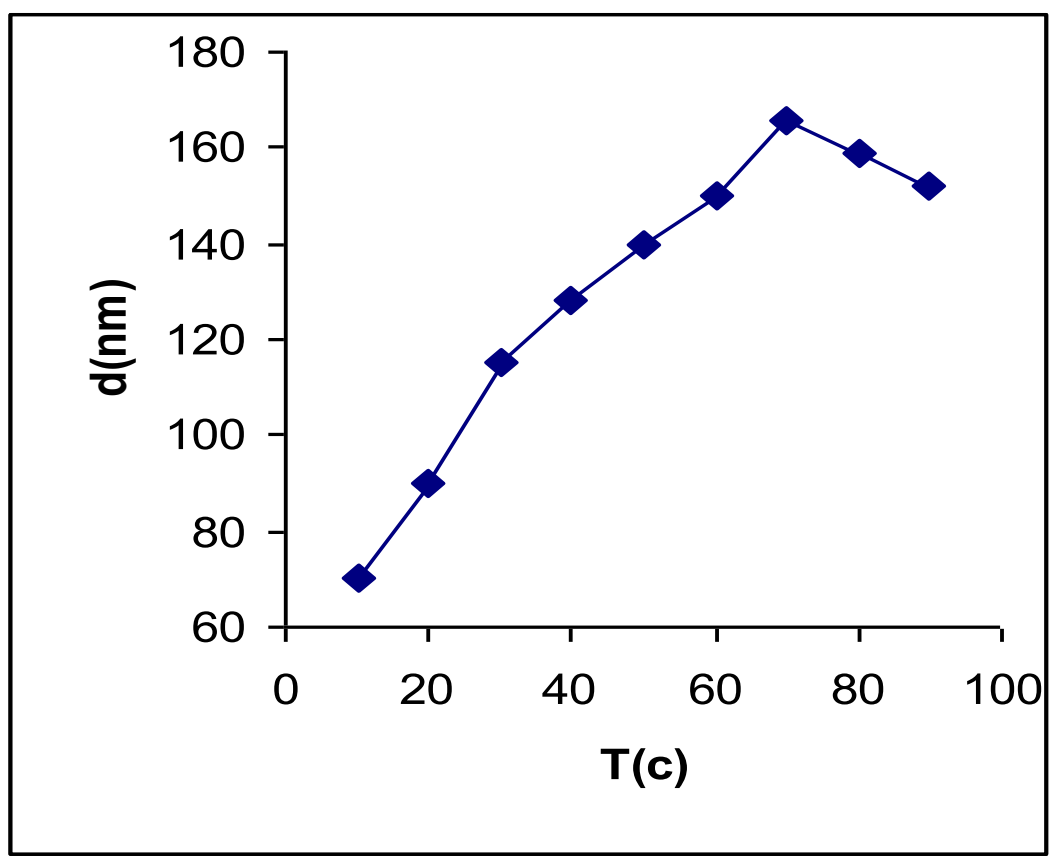

(b)

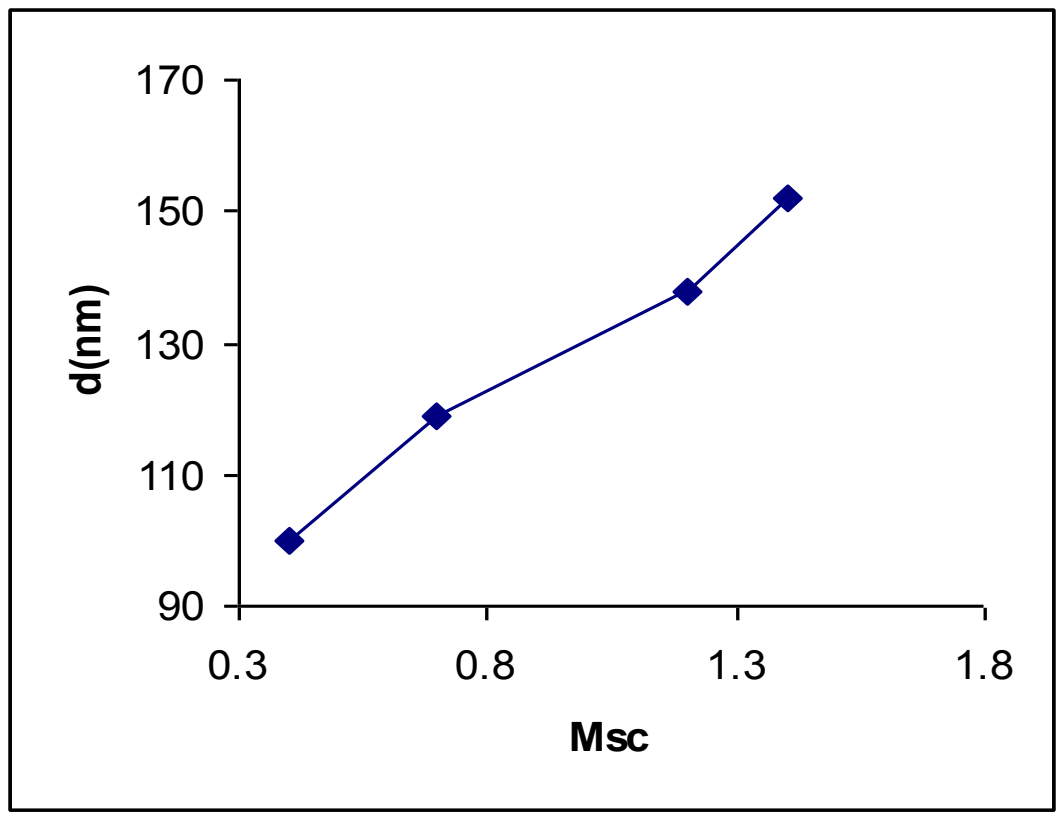

(c)

The concentration of both reagents plays a crucial role in the deposition process as shown in Figures 1 (e, f). We find out that the film thickness increased linearly with thiourea molar percentage Fig. 1 (e). The films formation starts from concentration of $\mathrm{S}^{2-}$ ions lower than 0.3 which indicate that even with low $\mathrm{S}^{2-}$ molar concentrations the ionic product exceeds 
the solubility product. No saturation behavior shown within the limits of work. Average film thickness goes on decreasing as the lead molar concentration increased. The decreasing can be interpreted as follows. With increase $\mathrm{Pb}^{2+}$ content the general trend is the decreasing in activation energy (The minimum energy barrier that must be met for a chemical reaction to happen) due to the slowly moving of $\mathrm{Pb}^{2+}$ ions with little kinetic energy.

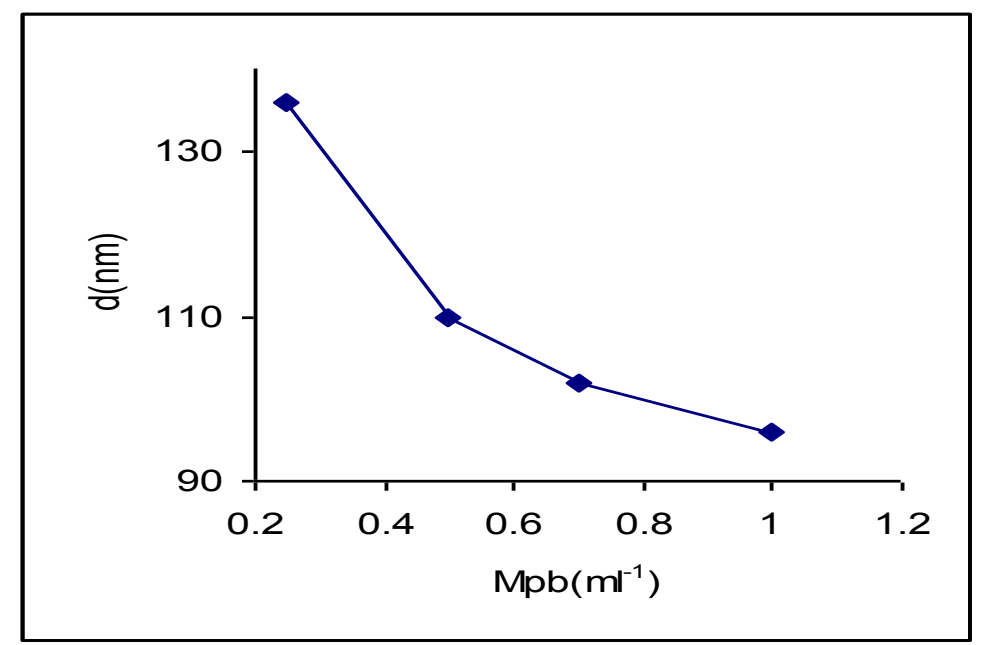

(d)

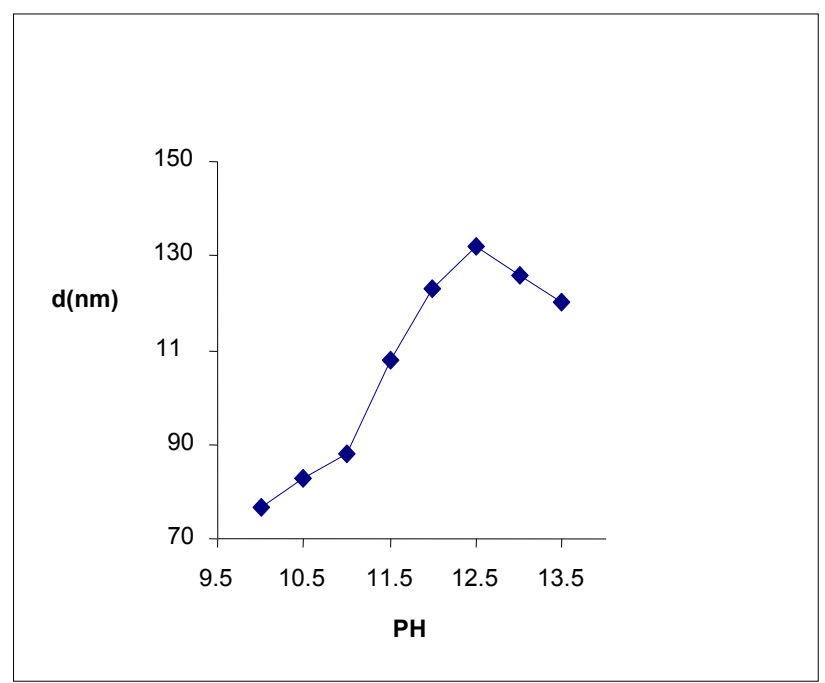

(e)

Fig. 1 (a-e). Thin film thickness as a function of (a) deposition time, (b) bath temperature, (c) molar concentration of thiourea, (d) lead molar concentration, (e) path $\mathrm{pH}$ value. 
The growth kinetics was also studied by keeping the path temperature at R.T. and deposition time of 30 minute. The deposition was made on varying the $\mathrm{pH}$ of the solution ranging from 10 to 13.5. It was found that the growth rate and the thickness of the film are highly dependent on the $\mathrm{pH}$ of the solutions as shown in Fig. (1c). the average growth rate is enhanced in the basic solutions, as the $\mathrm{pH}$ of the solution increases $(\mathrm{pH} \geq 11)$, the thickness of the film has been considerably increased up to $\mathrm{pH}=12.5$ and for more basic solution thickness decreased, and in this case the critical thickness around $130 \mathrm{~nm}$. This indicates that a gradual coverage of the substrate surface with $\mathrm{PbS}$ phases occurs, which results in increasing the number of possible sites available for the formation of nuclei determined by the composition and morphology of initial deposited layers. The enhanced deposition rate is probably due to the small change in Gibbs energy of nucleation between the first deposited $\mathrm{PbS}$ layers with the add deposited layer. One can see from Fig. 1(c) that with higher $\mathrm{pH}$ value $(>12.5)$ decreasing in film thickness takes place as in the work of Nuang et al (23).

\section{2. Band Gap}

In order to correlate the band gap values with the deposition conditions, we have deduced the band gap from the $(\alpha \mathrm{hv})^{2}$ as a function of (hv) plots (not shown here) (where $\alpha$ is the absorption coefficient ) through the extrapolation of the linear part of the curve. According to the effective mass approximation (24), the formation of Nano material controlled by two contradictory forces equ. (1). The first (contributing to the band gap increasing) is due to quantization effects in the conduction and valence bands is inversely proportional to $\mathrm{R}^{2}$ and increases as size decreases (where $\mathrm{R}$ is the nanocrystal radius), and the Coulomb energy shows that the band gap energy decreases with decreasing $\mathrm{R}$. the second term becomes dominant with small $\mathrm{R}$ i.e. when the particle size becomes comparable to or smaller than the Bohr exciton radius, the effective band gap is expected to increase with decreasing $R$,

$$
E_{g, \text { effective }}(R)=E_{g}(\infty)+\frac{\hbar^{2} \pi^{2}}{2 R^{2}}\left(\frac{1}{m_{e}}+\frac{1}{m_{h}}\right)-\frac{1.8 e^{2}}{\varepsilon R}
$$

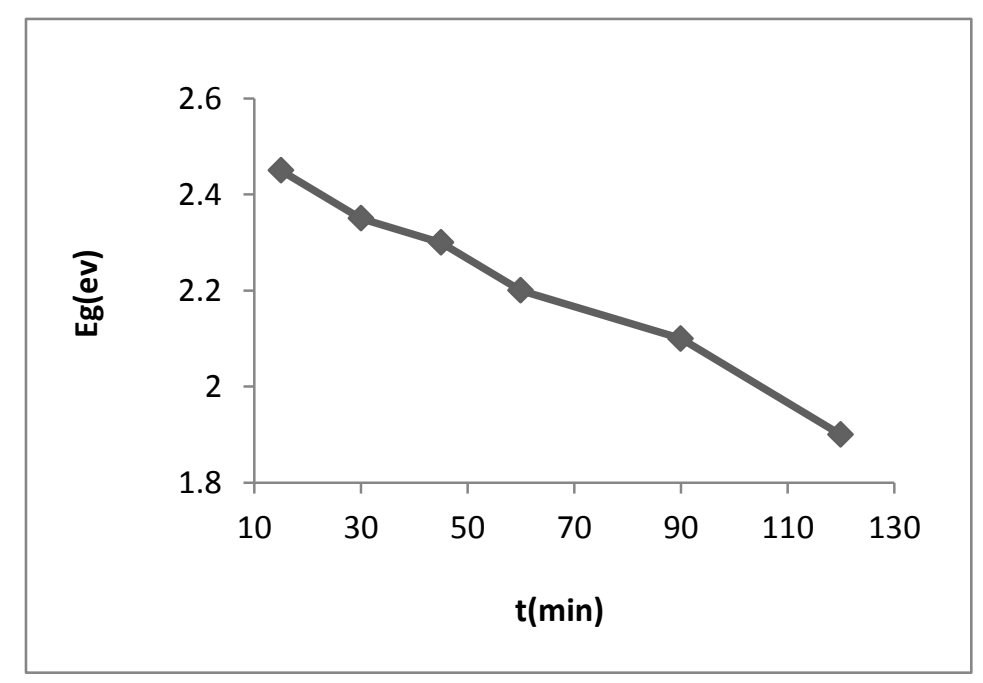

(a) 


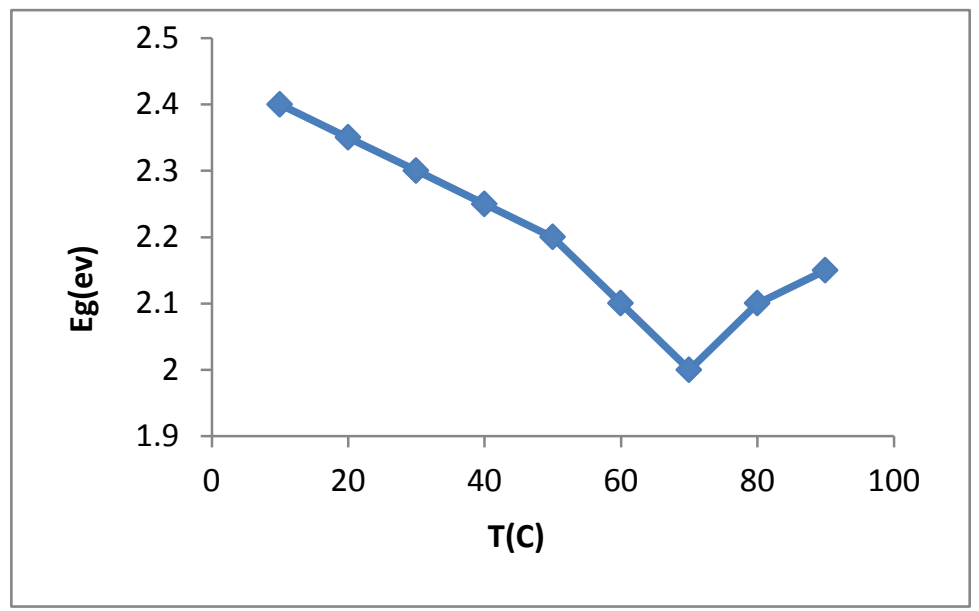

(b)

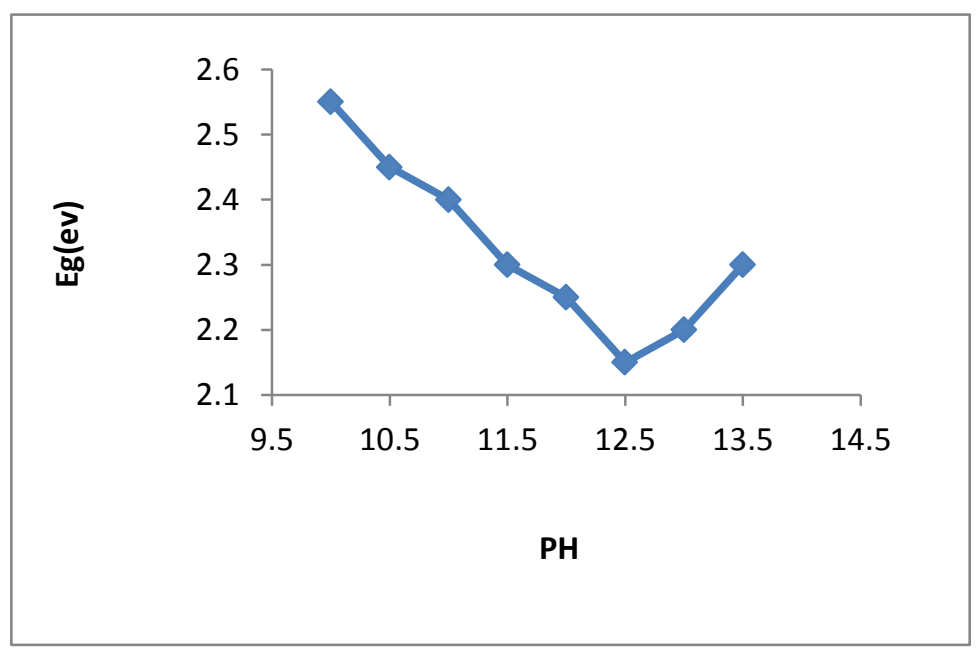

(c)

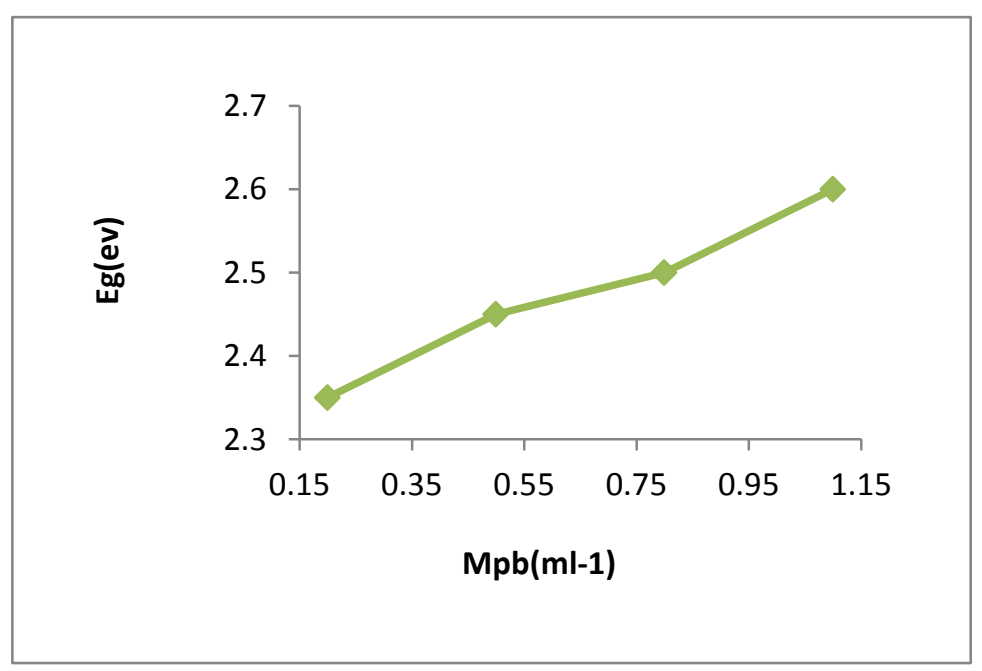

(d) 


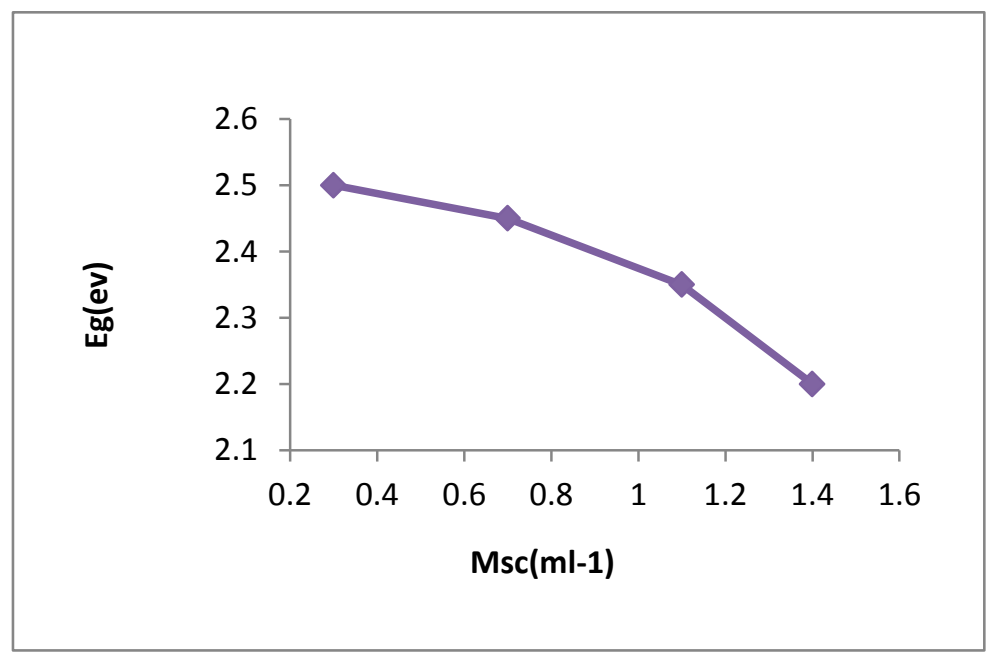

(e)

Fig. 2. Band gap of deposited film as a function of (a)deposition time, (b) bath temperature, (c) pH of the bath, (d) Lead molar value, (e) Molar value of thiorua.

\section{CONCLUSIONS}

$\mathrm{PbS}$ films have been prepared on glass substrates by Chemical bath deposition. By investigating the influence of deposition parameters on the kinematics of the deposited films, we obtained that the deposition rate was dominated by four factors: deposition time, temperature of deposition bath, $\mathrm{pH}$ of the deposition bath and the concentration of constituents. The higher the bath temperature is, the higher the reaction rate. The longue the deposition time is the higher the deposition rate, the reaction rate increased very significantly as the $\mathrm{pH}$ of the deposition bath increased. The growth rate can be controlled "fast" and "slow" by controlling the amount of $\mathrm{S}^{-2}$ in the reaction mixture. Despite the energy gap of the studied samples revealed a strong dependence of the Gaps values of the films on the deposition parameters, , it is possible to produce thin films of $\mathrm{PbS}$, with energy band gaps in the range 1.9-2.55 eV, and with proper manipulation of reaction parameters could be near to the optimum for photovoltaic energy conversion $(1.5 \mathrm{eV})$. Synthesis under identical reaction time scale (30 min) and keeping all other parameters identical confirms the faster growth of $\mathrm{PbS}$ with higher amounts of free $\mathrm{S}^{-2}$ in the reaction mixture.

\section{References}

[1] C. B. Honsberg, A. M. Barnett1, D. Kirkpatrick; NANOSTRUCTURED SOLAR CELLS FOR HIGH EFFICIENCY PHOTOVOLTAICS. 4th World Conference on Photovoltaic Energy Conversion, Hawaii, May 7-12, 2006.

[2] A. L. Efros, A.L. Efros, Fizika i Tekhnika Poluprovodnikov 16 (1982) 1209.

[3] L. E. Brus, J. Chem. Phys. 80 (1984) 4403.

[4] C. B. Murray, C. R. Kagan, M. G. Bawendi, Ann. Rev. Materials Science 30 (2000) 545. 
[5] N. Zaitseva, Z. R. Dai, F. R. Leon, D. Krol, J. Am. Chem. Soc. 127 (2005) 10221.

[6] C. Burda, X. B. Chen, R. Narayanan, M. A. El-Sayed, Chem. Rev. 105 (2005) 1025.

[7] J. Z. Zhang, Acc. Chem. Res. 30 (1997) 423.

[8] K. K. Nanda, F. E. Kruis, H. Fissan, M. Acet, J. Appl. Phys. 91 (2002) 2315.

[9] D. L. Partin, J. Heremans, in: T.S. Moss, S. Mahajan (Eds.), Handbook on Semiconductors, Vol. 3, Elsevier, Amsterdam, 1994, p. 369.

[10] A. Osherov, V. Ezersky, Y. Golan, Journal of Crystal Growth 308 (2007) 334-339.

[11] S. Seghaier, N. Kamouna, R. Brini, A. B. Amarac, Materials Chemistry and Physics 97 (2006) 71-80.

[12] Y. J. Yang, S. Hu, Thin Solid Films 516 (2008) 6048-6051.

[13] Anna Osherov, Janos P Makai, Janos Balazs, Zsolt J. Horvath, Nadav Gutman, Amir Sa'arand Yuval Golan, J. Phys.: Condens. Matter 22 (2010) (1-6).

[14] H. Zhang, D. Yang, Journal of Crystal Growth 263 (2004) 372.

[15] Ali M. Mousa, Shams B. Ali, Iraqi J. of Appl. Phys. 4 (2008) 1.

[16] B. R. Sankagal, C. D. Lokhande, Materials Chemistry and Physics 14 (2002) 126.

[17] A. P. Gaiduk, P. I. Gaiduk, A. N. Larsen, Thin Solid Films 516 (2008) 3791-3795.

[18] A. U. Ubale, A. R. Junghare, N. A. Wadibhasme, A. S. Daryapkar, R. B. Mankar, V. S. Sangawar, Turk J Phys 31 (2007) 279-286.

[19] R. S. Patil, H. M. Pathan, T. P. Gujar, C. D. Lokhande, J. Mater. Sci. 41 (2006) 5723.

[20] S. Seghaier, N. Kamouna, R. Brini, A. B. Amara, Mater. Chem. Phys. 97 (2006) 71.

[21] A. A. Rempel, N. S. Kozhevnikovab, A. J. G. Leenaersa, S. van den Berghe, J. Cryst. Growth 280 (2005) 300.

[22] P. O'Brien, J. McAleese, J. Mater. Chem. 8 (11) (1998) 2309.

[23] Gui-Fang Huang, Wei-Qing Huang, Ling-Ling Wang, Bing-Suo Zou, Qiao-Ling Wang, Jian-Hui Zhang, Int. J. Electrochem. Sci. 3 (2008) 145-153.

[24] Luttinger J. M., Kohn W., Phys. Rev. 97 (1955) 869.

[25] Nadir Fadhil Habubi, Sami Salmann Chiad, Saad Farhan Oboudi, Ziad Abdulahad Toma, International Letters of Chemistry, Physics and Astronomy 4 (2013) 1-8.

[26] Saad F. Oboudi, Nadir F. Habubi, Ghuson H. Mohamed, Sami S. Chiad, International Letters of Chemistry, Physics and Astronomy 8(1) (2013) 78-86.

[27] J. A. Najim, J. M. Rozaiq, International Letters of Chemistry, Physics and Astronomy 10(2) (2013) 137-150.

[28] Majid H. Hassouni, Khudheir A. Mishjil, Sami S. Chiad, Nadir F. Habubi, International Letters of Chemistry, Physics and Astronomy 11 (2013) 26-37.

[29] K. K. Patankar, International Letters of Chemistry, Physics and Astronomy 1 (2014) $1-8$. 
[30] Hanan R. A. Ali, International Letters of Chemistry, Physics and Astronomy 8 (2014) 47-55.

[31] Raghad Y. Mohammed, S. Abduol, Ali M. Mousa, International Letters of Chemistry, Physics and Astronomy 10 (2014) 91-104.

[32] Raghad Y. Mohammed, S. Abduol, Ali M. Mousa, International Letters of Chemistry, Physics and Astronomy 11(2) (2014) 146-158. 